\title{
Developmental stability in Brassica cretica: the effect of crossing distance on fluctuating asymmetry in cotyledon morphology
}

\author{
G-Y Rao' ${ }^{1}$ S Andersson ${ }^{2}$ and B Widén ${ }^{2}$ \\ ${ }^{1}$ College of Life Sciences, Peking University, Beijing 100871, P.R. China; ${ }^{2}$ Department of Systematic Botany, University of Lund, \\ Östra Vallgatan 18-20, S-223 61 Lund, Sweden
}

In the present investigation of Brassica cretica, a wild relative of the cultivated cabbage, $B$. oleracea, we performed an extensive crossing experiment, involving self-pollinations, random outcrosses within populations and hybridizations between populations or species, to evaluate the relationship between crossing distance and developmental stability, estimated as the absolute difference between the right and left lobe of the cotyledons. The frequency distribution of the right-minus-left scores had a narrower peak than expected for normally-distributed data, but there was no directional asymmetry or antisymmetry. Despite evidence for inbreeding depression in seedling biomass and cotyledon size, the type of cross had negligible influence on cotyledon asymmetry. Separate analyses of between-population hybrids revealed differences among progenies from different pairs of populations and a tendency for the F1 hybrid means to decrease with the geographic distance separating the parent populations, but only for the two size variables. Based on these and other observations, we propose that the degree of cotyledon asymmetry is unrelated to genome-wide characteristics, such as the level of heterozygosity and genomic co-adaptation, and that cotyledon asymmetry is unrelated to the level of genetic stress experienced by each individual. Hence, there is no reason to consider measures of asymmetry as more sensitive indicators of genetic health than conventional fitness variables.

Heredity (2002) 88, 197-202. DOI: 10.1038/sj/hdy/6800027

Keywords: developmental stability; Brassica cretica; Brassica oleracea; fluctuating asymmetry; crossing distance; genomic co-adaptation; heterozygosity

\section{Introduction}

Developmental stability, ie the ability of an organism to buffer its development against environmental and genetic disturbances, has received considerable attention in ecology and evolutionary biology. The failure to correct for random accidents during development may be manifested as fluctuating asymmetry (FA), defined as small, non-directional deviations from bilateral or radial symmetry (Palmer and Strobeck, 1986). There is growing evidence that environmental and genetic stress can induce significant levels of developmental instability (Palmer and Strobeck, 1986; Palmer, 1996; Møller and Swaddle, 1997), suggesting that FA could serve as an early warning system for monitoring the effects of stress on populations of rare, declining species (Leary and Allendorf, 1989; Clarke, 1995). However, for FA to be a useful tool in conservation biology, it is necessary to understand the genetic basis of developmental stability.

Despite numerous attempts to partition the variation in FA into genetic and non-genetic components (Evans and Marshall, 1996; Windig, 1998; Woods et al, 1998; Per-

Correspondence: S Andersson, Department of Systematic Botany, University of Lund, Östra Vallgatan 18-20, S-223 61 Lund, Sweden. E-mail: stefan.andersson@sysbot.lu.se

Received 10 July 2001; accepted 24 October 2001 fectti and Camacho, 1999), there is still little consensus regarding the heritable basis of FA and other measures of developmental instability. Special attention has been given to the relationship between developmental stability and genome-wide features, such as heterozygosity or genomic co-adaptation (Clarke, 1993). The heterozygosity hypothesis, which predicts a disruption of homeostasis after inbreeding (Lerner, 1954), has been evaluated by relating FA to the level of homozygosity of individuals or populations (inferred from marker genes) (Leary et al, 1983; Palmer and Strobeck, 1986; Møller and Shykoff, 1999), or by performing controlled self- or cross-pollinations and then assessing the amount of FA in the offspring generation (Clarke et al, 1992; Sheridan and Pomiankowski, 1997; Hochwender and Fritz, 1999; Waldmann, 1999). According to the co-adaptation hypothesis, one would expect crosses between species or populations to increase FA through a breakup of co-adapted gene interactions (Graham and Felley, 1985; Ferguson, 1986; Clarke et al, 1992; Clarke, 1993).

Whether heterozygosity and genomic co-adaptation influence measures of developmental stability is still unclear. Available data indicate a tendency for FA to increase with inbreeding (Palmer and Strobeck, 1986; Møller and Shykoff, 1999; Waldmann, 1999) and hybridization between species (Graham and Felley, 1985; Wilsey et al, 1998; Hochwender and Fritz, 1999) or popu- 
lations (Waldmann, 1999), but several studies report exceptions to these patterns (eg, Lamb et al, 1990; Clarke et al, 1992; Sheridan and Pomiankowski, 1997). Based on a meta-analysis of data from 41 studies (Vøllestad et al, 1999), heterozygosity seems to explain a small amount of the variation in FA among individuals or populations $\left(r^{2}=0.01\right)$. However, there are still too few experimental studies to draw general conclusions about the genetic basis of developmental stability and the use of FA as a tool in conservation biology.

Plants provide ideal organisms for experimental studies of developmental stability, particularly when large sample sizes are needed, but so far there have been few efforts to examine how FA responds to different crossing distances in the parent generation (Freeman et al, 1993; Wilsey et al, 1998; Hochwender and Fritz, 1999; Waldmann, 1999). In the present study of Brassica cretica Lam, a wild relative of the cultivated cabbage, $B$. oleracea $L$. (Lázaro and Aguinagalde, 1998), we have analysed progeny from an extensive crossing experiment, involving self-pollinations, random outcrosses within populations and crosses between populations or species, to assess the relationship between crossing distance and FA in cotyledon morphology. Because measures of asymmetry tend to be population- and environment-specific (Clarke, 1998), all crossing treatments were replicated across seven populations and all progeny were raised in the same environment. Computer-assisted image analysis was used to enhance the precision of the measurements.

\section{Materials and methods}

Brassica cretica is a diploid $(2 \mathrm{n}=18)$, partially self-incompatible chasmophyte with a native distribution in Greece (Crete, North Peloponnisos). The plants are perennial and up to $150 \mathrm{~cm}$ high, with white or yellow, insect-pollinated flowers that develop into siliqua. Preliminary analyses of electrophoretic variation show that B. cretica is outcrossing (few deviations from Hardy-Weinberg equilibrium) and that populations on Crete have undergone extensive divergence at allozyme loci (mean $\mathrm{F}_{\mathrm{ST}}=0.61$, B Widén, unpublished data; see also Lázaro and Aguinagalde, 1998).

The present investigation is based on seeds collected in 1991-1994 from 15-30 spatially separated ( $>10 \mathrm{~m}$ ) plants within each of seven Cretan populations (Table 1). Six randomly chosen seedlings from each maternal plant were planted in pots and randomized in a greenhouse, to serve as a base population for a large crossing experiment. To extend the range of crossing distances, we also

Table 1 The seven Cretan populations of Brassica cretica used in the present study

\begin{tabular}{lccc}
\hline $\begin{array}{l}\text { Population/ } \\
\text { location }\end{array}$ & $\begin{array}{c}\text { Latitude } \\
\left({ }^{\circ} \mathrm{N}\right)\end{array}$ & $\begin{array}{c}\text { Longitude } \\
\left({ }^{\circ} \mathrm{E}\right)\end{array}$ & $\begin{array}{c}\text { No. of } \\
\text { seed plants }\end{array}$ \\
\hline 1 Topolia & $35^{\circ} 27^{\prime}$ & $23^{\circ} 40^{\prime}$ & 23 \\
2 Roka & $35^{\circ} 29^{\prime}$ & $23^{\circ} 43^{\prime}$ & 15 \\
3 Macheri & $35^{\circ} 25^{\prime}$ & $24^{\circ} 07^{\prime}$ & 18 \\
4 Miliardo & $35^{\circ} 05^{\prime}$ & $25^{\circ} 24^{\prime}$ & 17 \\
5 Gonies & $35^{\circ} 14^{\prime}$ & $25^{\circ} 27^{\prime}$ & 27 \\
6 Monastriaki & $35^{\circ} 05^{\prime}$ & $25^{\circ} 50^{\prime}$ & 18 \\
7 Moni Kapsa & $35^{\circ} 01^{\prime}$ & $26^{\circ} 03^{\prime}$ & 30 \\
\hline
\end{tabular}

obtained plants of $B$. oleracea, derived from seeds collected in a wild population at Dartmouth, UK $\left(50^{\circ} 15^{\prime} \mathrm{N}\right.$, $\left.3^{\circ} 35^{\prime} \mathrm{W}\right)$.

The crossing experiment was performed in 1999 and involved four treatments: (1) self-pollination, (2) crosspollination with pollen from a randomly selected nonsib plant in the same population, (3) cross-pollination with pollen from a plant representing another population of $B$. cretica, and (4) cross-pollination with pollen from a plant of B. oleracea. Due to limited flower number, it was not possible to perform all crossing treatments within a single plant, making it necessary to randomize the crossing treatments across several maternal plants from each population. After the pollination procedures, all inflorescences were enclosed in transparent, perforated plastic bags to avoid pollen contamination. The fruits were collected 7-10 weeks after flowering. Asynchronous flowering and variable crossing success resulted in an unbalanced data set and a small number of crosses involving the Macheri population. To enhance balance in the progeny generation, we used a maximum of four progenies (hereafter referred to as 'families') from each treatment and recipient population, resulting in a total of 195 families.

In November 1999, six seedlings from each family were planted in separate pots with peat soil and placed in random positions in a greenhouse, followed by a second round of randomization 3 weeks later. Water was supplied as needed, but no fertilizer was applied. Plants were given supplementary light to minimize spatial variation in light intensity. Based on a separate study of $B$. cretica (G-Y Rao, S Andersson, B Widén, unpublished data), these growth conditions allow high survival rates without preventing the expression of inbreeding depression (G-Y Rao, unpublished data). When the cotyledons had attained maximum size (6 weeks after planting), all cotyledons were collected and pressed within a 1-day period. Two weeks later, all plants were harvested by clipping off all vegetative parts immediately above the node of the cotyledons. The above-ground biomass was recorded to the nearest $0.01 \mathrm{~g}$, after drying for 3 weeks at $40^{\circ} \mathrm{C}$.

The two-lobed cotyledons were measured with a video camera and image analysis software developed for Macintosh computers (IMAGEGRABBER ${ }^{\mathrm{TM}}$, OPTILAB ${ }^{\mathrm{TM}}$ ). Using the line connecting the indentation at the distal part of the cotyledon and the midpoint of the petiole as a symmetry line, we determined the area of the right and left lobe of each cotyledon and used the absolute value of the difference between the two sides (averaged over two cotyledons) to characterize the asymmetry of each individual, while the mean lobe area provided a measure of overall cotyledon size. The absolute asymmetries were subjected to a log transformation to meet the normality assumption in the parametric analysis. Data were obtained for 1100 plants.

To test for departures from 'ideal' FA (normally distributed deviations from a mean of zero, Palmer and Strobeck, 1986), we employed a bootstrap analysis with 2000 random samples from the original data set to calculate the $95 \%$ confidence interval (CI) of the moment statistics $\mathrm{g}_{1}$ and $\mathrm{g}_{2}$ (Sokal and Rohlf, 1995) and the mean of the right-minus-left (RL) scores. The null hypothesis of no skewness $\left(g_{1}=0\right)$, no kurtosis $\left(g_{2}=0\right)$ or no directional asymmetry (mean $\mathrm{RL}=0$ ), was rejected if any of these 
CIs excluded 0 . Measurement error was quantified by remeasuring the area of the right and left lobe on 102 of the cotyledons and then comparing the mean of the absolute differences between the repeat measurements with the mean of the absolute asymmetry values for this sample of cotyledons. A mixed model, two-way analysis of variance (ANOVA) was performed to determine whether the between-sides variance was significantly greater than the variance arising from measurement error (Palmer and Strobeck, 1986). Initial analyses revealed a weak, though significant, correlation between overall cotyledon area and log-transformed asymmetries of cotyledon area (Pearson $r=0.19, P<0.001$ ). To account for this scaling effect, we repeated all relevant analyses with 'relative asymmetries', obtained by dividing each asymmetry value by cotyledon area before the log transformation (Palmer and Strobeck, 1986).

Our data were subjected to nested, factorial analysis of variance (ANOVA), based on type III sum of squares, to evaluate the effects of (recipient) population, cross type, the interaction between population and cross type, and maternal family (nested within population and cross type), on each of the variables. These analyses were followed by separate ANOVAs of data from between-population hybrids to test for differences between crosses involving different pairs of populations. Cross type, population and population combination were considered as fixed effects, whereas family was regarded as random. Initial analyses of data from between-population crosses provided little evidence for reciprocal differences $(P>$ $0.35)$, so this factor was ignored in the final analyses.

In cases where a significant effect of population combination was detected ( $P<0.05)$, we employed a matrix permutation procedure to determine whether the mean of the F1 hybrids was significantly correlated with the genetic or geographic distance separating the parent populations. Genetic distances, quantified according to Nei (1978), were based on electrophoretically detectable variation at eight loci (number of alleles in parenthesis): Pgi-2 (3), Pgm-2 (5), Pgm-3 (3), Pgd-1 (3), Pgd-2 (5), Aco-1 (3), Aco-2 (5), Aco-4 (4) (analyses based on 25-46 plants per population; B Widén, unpublished data).

\section{Results}

The mean of the signed RL scores $(-0.532)$ and the skewness parameter $\left(g_{1}=0.009\right)$ were not significantly different from 0 , whereas the level of kurtosis $\left(g_{2}=1.997\right)$ reached significance (95\% CI excluding 0), suggesting a narrower peak than expected for normally-distributed data. Measurements of cotyledon lobe area were highly repeatable, with Pearson correlation coefficients exceeding 0.99 in all cases. Two-way ANOVA indicated a significant level of asymmetry relative to measurement error, as reflected by the significance of the cotyledon $\times$ side term (Table 2). Based on the mean of the absolute differences between the repeat measurements and the mean absolute asymmetry, the ratio of measurement error to cotyledon asymmetry was $13.1 \%$.

Seedling biomass differed greatly between treatment groups (Table 3), the mean being $0.39 \mathrm{~g}$ (s.d. $=0.18, n=$ 144) for selfed progeny, $0.49 \mathrm{~g}$ (s.d. $=0.15, n=126$ ) for plants from random outcrosses within populations, 0.58 g (s.d. $=0.17, n=763$ ) for between-populations hybrids, and $0.71 \mathrm{~g}$ (s.d. $=0.15, n=124)$ for hybrids between spe-
Table 2 Results of two-way ANOVA for repeatability of FA in

Brassica cretica cotyledon morphology. Entries are mean squares. Cotyledon was considered as random and side as fixed

\begin{tabular}{lrc}
\hline Source & $d f$ & Mean square \\
\hline Cotyledon & 101 & $7175.0^{* * *}$ \\
Side & 1 & $185.2 \mathrm{NS}$ \\
Cotyledon $\times$ side & 101 & $251.9^{* * *}$ \\
Measurement error & 204 & 2.3 \\
\hline
\end{tabular}

${ }^{* * *} P \leq 0.001, \mathrm{NS}=$ not significant $(P>0.05)$

cies. The significant population $\times$ cross type interaction (Table 3) can be attributed to the Miliardo and Gonies populations, which showed a negligible increase in seedling biomass after population or species hybridization (relative to the within-population outcrosses). Similar results were obtained for cotyledon area, even though the effect of crossing treatment failed to reach significance for this variable. Measures of cotyledon asymmetry were significantly affected by maternal family, but showed a non-significant influence of crossing treatment (Table 3).

Our analyses revealed significant differences between progenies representing different pairs of populations, but only for the size variables (Table 4). Judging from the matrix permutation tests, there was a tendency for the mean size of the hybrids (Table 5) to decrease with the geographic distance separating the parent populations (Table 6; Pearson $r=-0.36$ in both cases, $P<0.05$ ). Neither biomass nor cotyledon area covaried with the genetic distance between the populations (Tables 5, 6; Pearson $r=0.09-0.15, P>0.60)$. Given the non-significant effect of population combination (Table 4), no attempt was made to relate the mean asymmetry of each F1 family to the genetic or geographic distance between the parent populations.

\section{Discussion}

Estimates of FA are likely to be inflated over its true value owing to measurement error, the amount of bias depending on the accuracy of the measurements and the true level of asymmetry (Palmer and Strobeck, 1986). In the present investigation of cotyledon asymmetry, the between-sides variance was significantly greater than the variance arising from differences between repeat measurements, the ratio of measurement error to asymmetry being $13 \%$ for cotyledon area. In this context, it is also necessary to ask whether our data on cotyledon asymmetry conform to 'ideal' FA (normally distributed deviations from symmetry with a mean of zero). Our analyses provided little evidence for directional asymmetry or antisymmetry in the right-minus-left scores, but there was a larger number of observations around the mean than expected for a normal distribution, a common feature in studies of FA (Gangestad and Thornhill, 1999). Such deviations can be attributed to several factors, eg, limited resolution in the measurements and the pooling of groups that differ in asymmetry (Palmer and Strobeck, 1992; Houle, 1997; Waldmann, 1999). However, as no directional asymmetry or antisymmetry was detected, we consider cotyledon asymmetry as a potentially useful descriptor of developmental instability in B. cretica. Based on this assumption, we have compared the amount of 
Table 3 The effects of population $(\mathrm{P})$, cross type $(\mathrm{CT})$, their interaction $(\mathrm{P} \times \mathrm{CT})$ and family, on measures of Brassica cretica seedling size and cotyledon asymmetry, according to nested, factorial ANOVA. Entries are mean squares. Degrees of freedom in parentheses

\begin{tabular}{|c|c|c|c|c|c|}
\hline Variable & $\begin{array}{l}P \\
(6)\end{array}$ & $\begin{array}{l}C T \\
(3)\end{array}$ & $\begin{array}{c}P \times C T \\
(15)\end{array}$ & $\begin{array}{c}\text { Family } \\
(68)\end{array}$ & $\begin{array}{l}\text { Residual } \\
\text { (1011) }\end{array}$ \\
\hline Biomass & $0.252^{* * *}$ & $2.407^{* * *}$ & $0.147^{* *}$ & $0.051^{* * *}$ & 0.023 \\
\hline Cotyledon area & $17170.189^{* * *}$ & 20317.980 NS & $11880.992^{* * *}$ & $2874.663^{* * *}$ & 1184.431 \\
\hline Asymmetry in area & $0.584 \mathrm{NS}$ & $1.799 \mathrm{NS}$ & $0.717 \mathrm{NS}$ & $0.708^{*}$ & 0.512 \\
\hline Relative asymmetry in area & $2.007^{*}$ & $0.353 \mathrm{NS}$ & $0.711 \mathrm{NS}$ & $0.781^{* *}$ & 0.502 \\
\hline
\end{tabular}

${ }^{*} P \leq 0.05,{ }^{* *} P \leq 0.01,{ }^{* * *} P \leq 0.001, \mathrm{NS}=$ not significant $(P>0.05)$

Table 4 Results of nested ANOVA on data from between-population hybrids of Brassica cretica. Entries are mean squares. Degrees of freedom in parentheses

\begin{tabular}{|c|c|c|c|}
\hline Variable & $\begin{array}{c}\text { Population } \\
\text { combination } \\
\text { (19) }\end{array}$ & $\begin{array}{c}\text { Family } \\
\text { (108) }\end{array}$ & $\begin{array}{l}\text { Residual } \\
\text { (593-635) }\end{array}$ \\
\hline Biomass & $0.360^{* * *}$ & $0.054^{* * *}$ & 0.015 \\
\hline Cotyledon area & $10647.687^{*}$ & $5150.125^{* * *}$ & 763.457 \\
\hline $\begin{array}{l}\text { Asymmetry in } \\
\text { cotyledon area }\end{array}$ & $0.676 \mathrm{NS}$ & $0.652 \mathrm{NS}$ & 0.552 \\
\hline $\begin{array}{l}\text { Relative asymmetry } \\
\text { in cotyledon area }\end{array}$ & $0.792 \mathrm{NS}$ & 0.594 NS & 0.540 \\
\hline
\end{tabular}

${ }^{*} P \leq 0.05,{ }^{* * *} P \leq 0.001, \mathrm{NS}=$ not significant $(P>0.05$.

Table 5 Mean biomass ( $\mathrm{g}$, below the diagonal) and cotyledon area $\left(\mathrm{mm}^{2}\right.$, above the diagonal) for hybrids from crosses between different pairs of Brassica cretica populations. Entries are least-square means from ANOVA

\begin{tabular}{lccccccc}
\hline Population & 1 & 2 & 3 & 4 & 5 & 6 & 7 \\
\hline 1 Topolia & $\backslash$ & 185.4 & - & 167.8 & 167.3 & 163.8 & 151.4 \\
2 Roka & 0.564 & $\backslash$ & 175.2 & 194.4 & 213.4 & 139.2 & 168.8 \\
3 Macheri & - & 0.587 & $\backslash$ & 159.7 & 186.2 & 149.4 & 175.1 \\
4 Miliardo & 0.672 & 0.623 & 0.655 & $\backslash$ & 189.1 & 181.7 & 166.5 \\
5 Gonies & 0.604 & 0.652 & 0.773 & 0.758 & $\backslash$ & 182.8 & 182.5 \\
6 Monastriaki & 0.541 & 0.419 & 0.504 & 0.671 & 0.598 & $\backslash$ & 166.9 \\
7 Moni Kapsa & 0.484 & 0.401 & 0.470 & 0.586 & 0.590 & 0.478 & $\backslash$ \\
\hline
\end{tabular}

- , no progeny.

Table 6 Genetic and geographic distances between populations of Brassica cretica. Geographic distances (above the diagonal) measured to the nearest $\mathrm{km}$. Genetic distances (below the diagonal) expressed as Nei's (1978) unbiased genetic identity

\begin{tabular}{lccccccc}
\hline Population & 1 & 2 & 3 & 4 & 5 & 6 & 7 \\
\hline 1 Topolia & $\backslash$ & 7.65 & 39.3 & 198.2 & 203.4 & 239.0 & 259.8 \\
2 Roka & 0.771 & $\backslash$ & 36.2 & 196.4 & 201.6 & 237.2 & 258.0 \\
3 Macheri & 0.809 & 0.722 & $\backslash$ & 161.3 & 166.5 & 202.1 & 222.9 \\
4 Miliardo & 0.877 & 0.890 & 0.709 & $\backslash$ & 17.3 & 39.9 & 61.5 \\
5 Gonies & 0.562 & 0.448 & 0.481 & 0.535 & $\backslash$ & 38.0 & 59.1 \\
6 Monastriaki & 0.788 & 0.567 & 0.601 & 0.674 & 0.698 & $\backslash$ & 21.0 \\
7 Moni Kapsa & 0.776 & 0.488 & 0.675 & 0.589 & 0.627 & 0.895 & $\backslash$ \\
\hline
\end{tabular}

cotyledon asymmetry of plants derived from selfing, outcross pollination within populations and hybridization between populations or species, to evaluate the importance of heterozygosity and genomic co-adaptation in determining patterns of variation in developmental instability.

Before addressing this issue, it is necessary to emphasize that the type of cross exerted a significant effect on seedling vigour. First, we found selfed offspring to produce smaller cotyledons and a lower biomass than plants derived from random outcrosses within populations. Second, seedling biomass and cotyledon area were higher for hybrids between populations or species relative to offspring from within-population crosses. Third, there was a tendency for hybrids between geographically distant populations to produce smaller-sized progeny than crosses between adjacent populations. Collectively, these observations can be attributed to: (i) the increased expression of deleterious recessive alleles after self-pollination (or short-range crosses) and the masking of such genes in offspring representing longer crossing distances (Charlesworth and Charlesworth, 1987), and (ii) the possible disruption of co-adapted gene interactions in the longest-distance crosses (Graham and Felley, 1985; Alados et al, 1998; Wilsey et al, 1998; Hochwender and Fritz, 1999). Hence, to the extent that measures of seedling size are correlated with overall plant vigour, it seems that the shortest and longest crossing distances induced significant levels of stress in the progeny generation.

Despite large sample sizes and evidence for genetic stress in early plant vigour, we found no consistent effect of crossing treatment on the level of developmental stability in the offspring generation. The mean cotyledon asymmetry was the same regardless of whether the pollen came from the seed parent, from an unrelated plant in the same or another population, or from a plant of $B$. oleracea, and there was no significant variation in cotyledon asymmetry among plants from different betweenpopulation crosses. Given these and other observations, eg the lack of association between petal and cotyledon asymmetry (G-Y Rao, S Andersson, B Widén, unpublished data), it appears that genome-wide characteristics, such as heterozygosity and genomic co-adaptation, play a minor role in determining levels of cotyledon asymmetry and that cotyledon asymmetry is unrelated to the level of genetic stress experienced by each individual.

It is important to stress that all progenies experienced favourable greenhouse conditions, a factor that usually decreases the detectable effects of genetic stress (eg Dudash, 1990), and that no attempt was made to assess asymmetry in later-generation hybrids (cf. Hochwender and 
Fritz, 1999; Fenster and Galloway, 2000). Furthermore, we cannot rule out the possibility that differences between the two sides of each cotyledon are more strongly determined by plastic responses to different light conditions than by random accidents during development, ie that cotyledon asymmetry is a poor measure of developmental instability (Whitlock, 1996; Van Dongen, 1998). However, even though leaf structures show a weaker association between FA and genetic stress than floral organs (Møller and Shykoff, 1999; Waldmann, 1999), there is clear evidence from other species that genetic stress can induce significant levels of FA in foliar characters (Wilsey et al, 1998; Hochwender and Fritz, 1999).

Previous work has shown conflicting results as regards the genetic basis of developmental stability. Several authors have demonstrated increased levels of FA after inbreeding (Palmer and Strobeck, 1986; Møller and Shykoff, 1999; Waldmann, 1999) or hybridization (Graham and Felley, 1985; Wilsey et al, 1998; Hochwender and Fritz, 1999; Waldmann, 1999), while a number of studies report no or very weak effects (eg Lamb et al, 1990; Clarke et al, 1992). Moreover, a recent meta-analysis (Vøllestad et al, 1999) revealed only a weak association between heterozygosity and FA, regardless of whether heterozygosity was estimated using enzyme electrophoresis or inbreeding coefficients. In view of these observations and the results of the present investigation, there is no reason to consider measures of asymmetry as more sensitive indicators of genetic health than more conventional fitness variables. Consequently, we urge caution in the use of FA as a surrogate for direct components of fitness when monitoring the effects of inbreeding or hybridization on natural populations (cf. Leary and Allendorf, 1989; Clarke, 1995).

\section{Acknowledgements}

We are indebted to Laura Bergvall, Gabrielle Rosquist, Linus Svensson and Marie Widén for their assistance in the field, Honor C Prentice for providing seeds of B. oleracea, Marie Widén for performing experimental crosses, and Alf Ceplitis and Rune Svensson for taking care of the plants in the greenhouse. This study was supported by SJFR grant no. 33.0141/95 (to BW) and a scholarship from the scholar exchange program between Lund University and Peking University (to GYR).

\section{References}

Alados CL, Navarro T, Cabezudo B, Emlen JM, Freeman DC (1998). Developmental instability in gynodioecious Teucrium lusitanicum. Evol Ecol 12: 21-34.

Charlesworth D, Charlesworth B (1987). Inbreeding depression and its evolutionary consequences. Ann Rev Ecol Syst 18 237-268.

Clarke GM (1993). The genetic basis of developmental stability. I. Relationships between stability, heterozygosity and genomic coadaptation. Genetica 89: 15-23.

Clarke GM (1995). Relationships between developmental stability and fitness: Application for conservation biology. Cons Biol 9: 18-24.

Clarke GM (1998). The genetic basis of developmental stability. IV. Individual and population asymmetry parameters. Heredity 80: 553-561.

Clarke GM, Oldroyd BP, Hunt P (1992). The genetic basis of developmental stability in Apis mellifera: Heterozygosity versus genic balance. Evolution 46: 753-762.
Dudash MR (1990). Relative fitness of selfed and outcrossed progeny in a self-compatible, protandrous species, Sabatia angularis L. (Gentianaceae): a comparison in three environments. Evolution 44: 1129-1139.

Evans AS, Marshall M (1996). Developmental instability in Brassica campestris (Cruciferae): fluctuating asymmetry of foliar and floral traits. J Evol Biol 9: 717-736.

Fenster CB, Galloway LF (2000). Population differentiation in an annual Legume: genetic architecture. Evolution 54: 1157-1172.

Ferguson MM (1986). Developmental stability of rainbow trout hybrids: genomic coadaptation or heterozygosity? Evolution 40: 323-330.

Freeman DC, Graham JH, Emlen JM (1993). Developmental stability in plants: symmetry, stress and epigenesis. Genetica 89: 97-119.

Gangestad SW, Thornhill R (1999). Individual differences in developmental precision and fluctuating asymmetry: a model and its implications. J Evol Biol 12: 402-416.

Graham JH, Felley JD (1985). Genomic coadaptation and developmental stability within introgressed populations of Enneacanthus gloriosus and E. obesus (Pisces, Centrarchidae). Evolution 39: 283-289.

Hochwender CG, Fritz RS (1999). Fluctuating asymmetry in a Salix hybrid system: the importance of genetic versus environmental causes. Evolution 53: 408-416.

Houle D (1997). Comment on 'A meta-analysis of the heritability of developmental stability' by Møller and Thornhill. J Evol Biol 10: 17-20.

Lamb T, Novak JM, Mahoney DL (1990). Morphological asymmetry and interspecific hybridization: a case study using hylid frogs. J Evol Biol 3: 295-309.

Lázaro A, Aguinagalde I (1998). Genetic diversity in Brassica oleracea L. (Cruciferae) and wild relatives $(2 \mathrm{n}=18)$ using isozymes. Annals of Botany 82: 821-828.

Leary RF, Allendorf FW, Knudsen KL (1983). Developmental stability and enzyme heterozygosity in rainbow trout. Nature 301: 71-72.

Leary RF, Allendorf FW (1989). Fluctuating asymmetry as an indicator of stress: implications for conservation biology. Trends Ecol Evol 4: 214-217.

Lerner IM (1954). Genetic Homeostasis. John Wiley and Sons: New York.

Møller AP, Swaddle JP (1997). Asymmetry, Developmental Stability, and Evolution. Oxford University Press: Oxford.

Møller AP, Shykoff JA (1999). Morphological developmental stability in plants: Patterns and causes. Int J Plant Sci $\mathbf{1 6 0}$ (Suppl): S135-S146.

Nei M (1978). Estimation of average heterozygosity and genetic distance from a small number of individuals. Genetics 89: 583-590.

Palmer AR (1996). Waltzing with asymmetry: is fluctuating asymmetry a powerful new tool for biologists or just an alluring new dance step? BioScience 46: 518-532.

Palmer AR, Strobeck C (1986). Fluctuating asymmetry: measurement, analysis, patterns. Ann Rev Ecol Syst 17: 391-421.

Palmer AR, Strobeck C (1992). Fluctuating asymmetry as a measure of developmental stability: implication of non-normal distributions and power of statistical tests. Acta Zool Fenn 191: 57-72.

Perfectti F, Camacho JPM (1999). Analysis of genotypic differences in developmental stability in Annona cherimola. Evolution 53: 1396-1405.

Sheridan L, Pomiankowski A (1997). Fluctuating asymmetry, spot asymmetry and inbreeding depression in the sexual coloration of male guppy fish. Heredity 79: 515-523.

Sokal RR, Rohlf FJ (1995). Biometry, 3rd edn. Freeman: New York.

Van Dongen S (1998). How repeatable is the estimation of developmental stability by fluctuating asymmetry? Proc $R$ Soc Lond B 265: 1423-1427.

Vøllestad L, Hindar K, Møller AP (1999). A meta-analysis of 
fluctuating asymmetry in relation to heterozygosity. Heredity 83: 206-218.

Waldmann P (1999). The effect of inbreeding and population hybridization on developmental instability in petals and leaves of the rare plant Silene diclinis (Caryophyllaceae). Heredity 83: 138-144.

Whitlock M (1996). The heritability of fluctuating asymmetry and the genetic control of developmental stability. Proc $R$ Soc Lond B 263: 849-854.
Wilsey BJ, Haukioja E, Koricheva J, Sulkinoja M (1998). Leaf fluctuating asymmetry increases with hybridization and elevation in tree-line birches. Ecology 79: 2092-2099.

Windig JJ (1998). Evolutionary genetics of fluctuating asymmetry in the peacock butterly (Inachis io). Heredity 80: 382-392.

Woods RE, Hercus MJ, Hoffmann AA (1998). Estimating the heritability of fluctuating asymmetry in field Drosophila. Evolution 52: 816-824. 